\title{
Challenging Perceptions on Body Image Using a Bariatric Weighted Suit with Female University Dancers
}

\begin{abstract}
Keywords: Body image; Bariatric weighted suits; University students; Female dancers

Abstract

Body image concems of female dancers have gained a considerable amount of attention due to issues associated with the need to meet the industry's demand of a particular physique and appearance to impress audiences. This study was therefore designed to challenge perceptions of body image whilst wearing dancing in a bariatric weighted suit. $\mathrm{n}=15$ Undergraduate BSc (Hons) Degree Sport and Dance and Performing Arts students ( $x \pm$ s; age $=20.5 \pm 0.8$ years) were recruited. Participants danced in a specifically designed 3 minute routine and completed an adapted pre-validated Body Esteem Scale (BES) questionnaire before and after wearing a bariatric weighted suit. Results indicated that before dancing in the bariatric weighted suit none of the dancers were "satisfied" with their body appearance. When participants were asked whether the media had an effect on their opinion of their body image $46.7 \%$ stated that the media did have an effect to have a particular body image. $66 \%$ of the participants wanted to change their stomach before dancing in the bariatric weighted suit which decreased to $40 \%$ after dancing in the bariatric weighted suit. In conclusion, findings revealed that using the bariatric weighted suit had a positive effect on the female dancer's perception on their body image. Results found that wearing the bariatric weighted suit made them appreciate that their body was not as bad as they first perceived and that they felt more confident and comfortable with their body after the study. Suggestions for future research with the bariatric weighted suit could be used with young females who are at risk of becoming obese and what could happen to their physic al movement, health and appearance if they fail to act, furthemore, with non-dancers or males to challenge theirperceptions.
\end{abstract}

\section{Introduction}

The perception of body image has evolved over the years, and what was considered to be an ideal image sixty years ago differs to now [1]. It has changed from being very slender and petite to curvaceous then to the slim figure. Peterson suggests that everyone is affected daily by body image, and provide negative effects are that females may be encouraged to appear a particular shape and size that may be unrealistic for individuals to achieve, because genetically it may not be physically possible $[2,3]$. Thompson and Gardner perceive the pressures of body image as demoralising which creates a considerable amount of pressure on the individual leading to eating disorders [4]. Whereas Tiggemann implies that one of the positive effects of body image is that it can encourage individuals to have an aspiration to work towards a target alongside health benefits [5]. Due to the positive and negative aspects on body image Blood [6] suggested that it becomes a challenging subject, as everyone has an opinion on whether it is
Journal of

Obesity and

Bariatrics

\section{Claire Mills* and Sarah Dee}

Faculty of Applied Sciences, University of Gloucestershire, Oxstalls Campus, Gloucester, GL2 9HW, UK

\section{*Address for Correspondence}

Claire Mills, Faculty of Applied Sciences, University of Gloucestershire, Oxstalls Campus, Gloucester, GL2 9HW, UK, Tel: +44 (0)1242 715156; Fax: +44 (0)1242 715222; E-mail: clairem@glos.ac.uk

Submission: 04 July, 2016

Accepted: 06 July, 2016

Published: : 11 July, 2016

Copyright: (c) 2016 Mills C et al. This is an open access article distributed under the Creative Commons Attribution License, which permits unrestricted use, distribution, and reproduction in any medium, provided the original work is properly cited.

Reviewed \& Approved by: Dr. Radwan Kassir, Department of General and Bariatric surgery, University Hospital Center of SaintÉtienne, France

their own appearance or a general perception. Rumsey and Harcourt believe that female celebrity's and their body shape have an effect on females' attitudes towards their body image because they naturally compare themselves [7]. As such with the media having created a society that has strong views on a female's body image this has placed significant amount of pressure on female's [8].

\section{Body image and media influences}

Due to media influence, the general population is likely to neglect their body to achieve a perceived body ideal. In particular, female dancers highlight the media pressures on the thin dancer internalization [9]. Bruns and Carter also recognize that media coverage is one of the main causes of body dissatisfaction within society [10]. Major changes in perceptions have altered how people see themselves and others because the media idealise body images with a sexual appeal [11]. As a consequence society has had a shift with more objectification and different opinions on ourselves and others greater than ever before [12]. There is a regression from the decade 2000 to thin figure for females which is signified attractive during that particular time, this is a negative revolution because it creates pressure on females to conform to a certain stereotype [8]. Maltby, Giles, Barber and McCutcheon agree that the regression is not natural because the media is recognized to promote unrealistic figures and glamorizing thin celebrities and models which create a considerable amount of pressure on females [13]. Over the years, females' relationship between the media stereotype of body image are conflicting and there is a constant struggle to achieve the ideal body [14]. Heiland, Murray and Edley also reinforce that the media generates a considerable amount of pressure, being slender and creating potential eating disorders especially within the dance community [15].

\section{Body image in female dancers}

Dancers are required to have a particular physique and appearance to meet the media's perception because they need to impress audiences 
[16,17]. As a consequence, this creates more pressure for female dancers to achieve a particular body image and may face dilemmas that if they do not have the appropriate physique this may lead to a negative self-evaluation [18]. However there are a variety of styles within dance, which do not have strict opinions on body image, such as hip hop [19]. Over the years hip hop dancers' body image evolved to encompass a variety of shapes and sizes and it has been argued that the body shape are more realistic to females today $[15,20]$. Jackson claim that more dance styles should be challenged to accept a wide range of body physiques in order to change society's stereotypical opinion of body image relating to that particular style [21]. Debates from Oliver and Radell et al. claim that although dancers can have a negative body image due to mediated pressures, dance can also create a positive body image and helps improve self-esteem for some dancers $[18,22]$. Therefore, one promising and new area of research is in the use of bariatric weighted suits, they could be the key to unlocking the females' perception of how their body feels and looks.

\section{The bariatric weighted suit}

Bariatric derives from the Greek word 'baro' meaning heavy or large and in today's society bariatrics has become known as a branch of medicine which deals with causes, prevention and treatment of obesity [23]. Simulated experiences of a bariatric individual are behind the main design of the bariatric weighted suit because it is adding to the natural weight of the individual [24]. Identified as an essential instrument, the bariatric training suit is used within the National Health Service (NHS) to develop nurse's training [25]. It has also become very helpful in a recent study by Leicester Royal Infirmary, by allowing nurses to develop specific skills to manage and combat the challenges of working with bariatric patients [26]. Training can allow the nurses to transfer patients to and from a commode, bed or chair, helping patients get out of bed or into bed [27]. Recognized by nurses, the bariatric suit is important to use because it is a realistic training mechanism to allow them to practice such techniques using realistic scenarios within a safe and controlled environment [27].

From a non-nursing point of view the weighted suit can be used to manipulate muscular power, strength or endurance relative to body weight [28]. Furthermore, the weighted suit has contributed to studies concerning muscle toning, weight reduction and improving posture, balance and power $[29,30]$. Research on such topics can lend itself to identifying and perhaps help to change individuals' perceptions on body image and self-perception [31]. The versatility of the suit depending on manufacturer can be designed to have numerous weight compartments that are positioned around various locations on the suit which accommodates an increase of up to $40 \mathrm{lbs}$, in order to provide a realistic experience [25]. The suit is designed to accommodate all body shapes and consists of three sections (see Figure 1). Firstly the padded legs with a $60 \mathrm{~cm}$ waist circumference with a pair of denim trousers, padded arms and weighted torso section with 6 XL sized sweater [25].

\section{Research of bariatric weighted suits to change people's perceptions}

Previous research by Mills investigated what it is like to be obese with the use of bariatric weighted suits in a physical activity environment [25]. One of the most pertinent findings from Mills

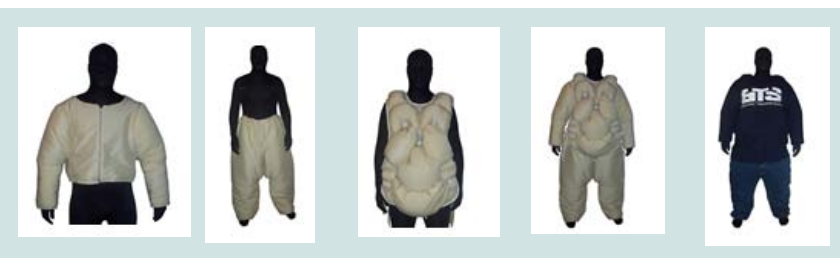

Figure 1: A bariatric weighted suit illustrating different components (Image retrieved from bariatric training suits [31]).

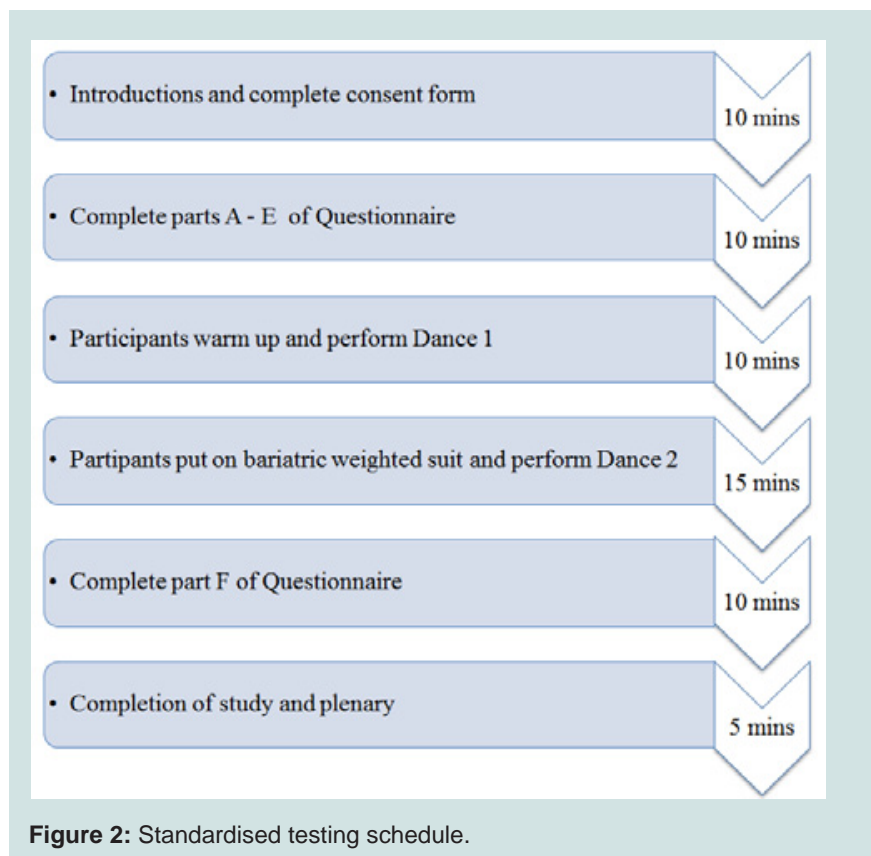

study highlighted that the participants had to deal with an abrupt customization of the weighted suit [25]. This customization saw heart rates (bpm) rise from $56 \mathrm{bpm}$ at rest, to $92 \mathrm{bpm}$ when wearing the suit to $148 \mathrm{bpm}$ after two minutes of low intensity exercise on a cycle ergometer. Results found that the weighted suit added considerable amount of stress on the heart with an increase of up to $164 \%$ (on average). From a mechanical point of view, participants had to also deal with adaptations of their running style whilst wearing the suit. Participants found wearing the suit stressful on their joints and posed challenges when moving from a standing to sitting position and particularly during $10 \mathrm{~m}$ sprint and Illinois Agility Run tests [25]. A limitation of Mills study was only eight participants were recruited and methodically speaking it was important to understand that there was an immediate weight increase for the participants within a short time frame [25]. However due to the increase of body image issues amongst female dancers and the low level of research using bariatric weighted suits, Mills study provides an opportunity to contribute to further research. This study aims to challenge the perceptions of dancer's body image before and after wearing a bariatric weighted suit whilst in a practical activity setting $[9,25]$.

\section{Materials and Methods}

\section{Participants and recruitment}

Fifteen students $(\mathrm{x} \pm \mathrm{s}$; age $=20.5 \pm 0.8$ years $)$ were recruited from 


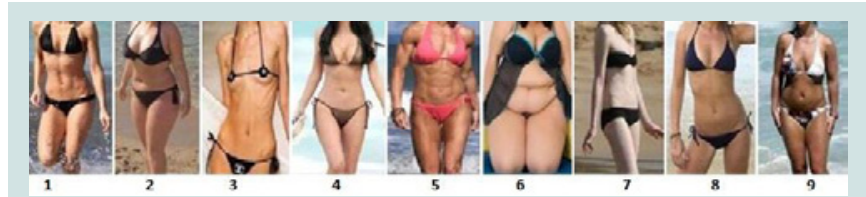

Figure 3: Part D questionnaire images which participants had to select from.

University of Gloucestershire Undergraduate BSc (Hons) Degree Sports Education and Dance and Performing Arts courses during 2015/2016 academic year. Selective and purposeful sampling took place to garner participants. All participants were given an informed consent form and an invitation to participate so that they understood their involvement and their right to withdraw. Consent was secured with a participant signature. Each participant was anonymised by number coding and ensured confidentiality with a password protected personal computer.

\section{Data collection}

Figure 2 exhibits the procedure that all of the participants followed to ensure a consistent approach. In brief, there were four elements: (1) to complete Parts A - E elements of a questionnaire, (2) to perform a dance routine, (3) to perform the same dance routine whilst wearing a bariatric weighted suit and (4) to complete Part F element of the questionnaire.

\section{Questionnaire}

This study took a qualitative approach using an adapted version of a pre-validated Body Esteem Scale (BES) questionnaire [32]. For the purpose of theming, the questionnaire was split into parts (part A - general appearance, B - attitude to body image, C - media influences on body image, D - self-perception of the female body, E body specifics before the dance routine and $\mathrm{F}$ - body specifics after the dance routine and wearing the bariatric weighted suit. As previously mentioned Parts A - E of the questionnaire were completed before dancing in the bariatric weighted suit and part $\mathrm{F}$ was after performing in it to identify body image issues.

\section{Dance routine}

To ensure consistency across the participants it was necessary to design a 3 minute dance routine which consisted of range of quick and slow movements so that the study had full control on the length of time and the movements required. Once the routine was created, it was uploaded to YouTube and the hyperlink (https://youtu.be/ ixHLOwI4WV4) emailed to participants so that they could become familiar with the routine. During testing, the dance routine was projected on to a large projector screen so that the participants could see and help them perform as accurately as possible.

\section{Data analysis}

Likert scores from the questionnaire were added to a Microsoft Excel (2010) spreadsheet to determine the mean, standard deviation and percentages for the overall sample. Breakdown analysis of the different parts of the questionnaire was generated from the closed questions. One open question was presented to provide a deeper understanding of the reaction from each participant dancing in the bariatric weighted suit and was analysed using themes and trends.

\section{Results and Discussion}

Female dancer's perceptions of body image was analysed to understand if the bariatric weighted suit challenged their opinions before and after performing a dance routine in a bariatric weighted suit and therefore presented in two sections:

First part of the questionnaire before the participants danced in the bariatric weighted suit

Questionnaire Part A - General appearance: $46.7 \%$ of the participants were "somewhat" happy with their body appearance, which could be interpreted that the dancers were unhappy with the way their body looks. Only a small margin of the participants (6.7\%) were "satisfied" with their body appearance and none (0\%) of the participants were "very satisfied" with their body. These findings are reflected in Nerini [9] research on female dancers which suggested that highlighted the media pressures on the thin dancer internalization.

Questionnaire Part B - attitude to body image before dancing in the bariatric weighted suit: The majority $(60 \%)$ of the participants wanted to change at least one part of their body. When asked whether they were happy with their bodies the leading answer was "somewhat", suggesting they felt a lack of confidence or dissatisfaction regarding their figure. Over the past ten years the media has had a large impact in creating concerns on perceptions of females' body image which consequently generates pressure on body image [33].

Questionnaire Part C - media influences on participant's body image: $93 \%$ of participants felt unhappy about their body appearance compared to professional dancers. Yet when asked if the media has an effect on their satisfaction of their body appearance, only $6.7 \%$ strongly believed that the media have an impact on their body perception. Further questions revealed that $73 \%$ of participants felt marginally pressured to have a specific body image and $13.3 \%$ felt pressured or very pressured ("satisfied" or "very satisfied") to have a particular body image. Indeed professional dancers have the pressure from the dance industry to meet the physical requirements to be slender with impeccable balance, grace, rhythm, and speed [34].

Questionnaire Part D - self-perception of the female body: Participants had to select the most and least attractive from a random selection of images which are very similar to what is presented in the media across the body image spectrum as illustrated in Figure 3. The female's least attractive image was reported at $60 \%$ as a severely underweight figure (number 3 from Figure 3 ) and the second least attractive image at $26.6 \%$ was a severely overweight figure (number 6 from Figure 3). These results are conflicting because the assumption would be that participant's would select the obese image because you could argue that women stress more about being overweight, however the underweight image was selected. Perhaps, this is because the media display underweight females within the dance industry, thus generating pressure on the dancer to look a certain way [35].

When reporting on the perceptions of what males would find the least attractive, participant's rated the severely overweight image as the body appearance that they believed males would find unattractive (number 6 from Figure 3). This may be because the media present obese women to be unattractive, therefore females assume that males would also agree and believe in that perception. In contrast when 
Citation: Mills C, Dee S. Challenging Perceptions on Body Image Using a Bariatric Weighted Suit with Female University Dancers. J Obes Bariatrics. 2016;3(1): 6.

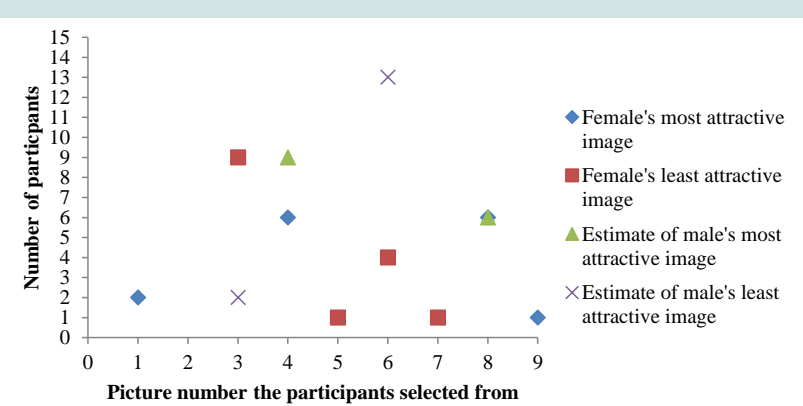

Figure 4: The correlation between female's perception of most and least attractive compared to the assumption of what they think males would find most and least attractive.

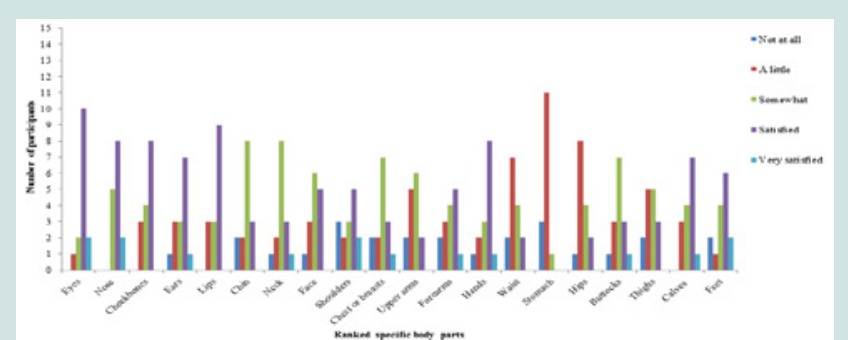

Figure 5: Participants rating on each body part before dancing in the bariatric weighted suit.

reporting on what males would find most attractive the image is varied between images 4 , and 8 (see Figure 4). There were different answers for the females' perception of least attractive images and also the females' perception of what males would find least attractive. Image 3 (see Figure 4 ) was chosen by $60 \%$ of the females as the least attractive image and also $13.4 \%$ thought that males would find this image as least attractive. However $86.7 \%$ of females perceived image 6 as the least attractive image to males. It is interesting to see that females find the very skinny image as unattractive and the females' perception of what males would find least attractive is the obese image.

\section{Questionnaire Part E - body specifics before dancing in the bariatric weighted suit}

None of the participants' rated that they were happy or content with their stomachs, with $73.3 \%$ of the participants disliking their stomachs (see Figure 5). This finding may be an affect from the media which have a considerable impact on the dancers' opinions on how their stomachs should look. According to Arnsperger if females have concerns about their stomachs they are also more likely to have a worry about their hips too [36]. 53.3\% of the participants stated that they were slightly unhappy about their hips (see Figure 5). The most attractive body part was the eyes at $66.7 \%$, however some may argue that although is represent part of the body, the eyes does not contribute to body image [37]. In a similar study females rated features located on the head as the most attractive area on the body and the least attractive was the stomach area [36]. In general, this highlights that females have a negative perception on their stomach area and positive perception on their facial features such as eyes.

It is apparent that the body part with the highest ranking was the chest, although it is not a high percentage at $26.7 \%$ (see Figure
5). There is a large range of personal perceptions on the attractive body areas amongst the participants because of the small percentage of each area, which means there are other body parts that have been ranked. The least attractive areas on Figure 5 highlight the most common disliked areas of the body in females [36]. Low percentages for these particular results indicate that females severely scrutinise themselves because of the pressure from the media. Therefore no specific least attractive areas are the same to all females. However Figure 6 indicates that $66.7 \%$ of the participants wanted to change the stomach, which is a significant amount. These results suggest that females desire to have a flat stomach because of the constant pressure from the media.

\section{Second part of the questionnaire after the participants danced in the bariatric weighted suit}

Questionnaire Part F - body specifics after dancing in the bariatric weighted suit: When comparing the rating for specific body parts, results indicated that the rating for the eyes decreased by $20 \%$ (see Figure 5). Consequently the bariatric weighted suit had an effect on the participants altering their feelings towards certain body parts. In Figure 6 the highest ranking disliked body part was the stomach however in Figure 6 this result decreased by $18.8 \%$ after dancing in the bariatric weighted suit. Participants may have changed their opinions after experiencing what it would be like to be severely overweight. Referring to Figure 6 the amount of "satisfied" results on body parts compared to previous answers prior to testing (see Figure 7) increased by $12.4 \%$. This rise may not be considered a significant quantity, but it reveals the females felt more satisfied on particular body parts after dancing in the bariatric weighted suit. The level of "not at all" results on body parts in Figure 6 compared to the findings in Figure 7 also increased by $21.2 \%$ however these findings show that the participants rated more parts negatively which was unexpected. After dancing in the bariatric weighted suit, lower parts of the body were rated negatively, suggesting that the testing may have prompted the participants' anxieties towards those areas because of excess weight. Similar results on the perceptions on specific anatomical areas and its contribution to their body image by Chacon-Araya and Moncada-Jimenez suggest that wearing the bariatric weighted suit positively changed their perceptions in specific body parts [37].

Figure 7 indicates that the chest was the most attractive anterior body part rated $6.66 \%$ higher than the previous results for the same body part in Figure 5. Results from Figure 8 exhibit the least attractive body part changed to the stomach with $26.7 \%$ which indicates the participants were more aware of their stomach area after dancing

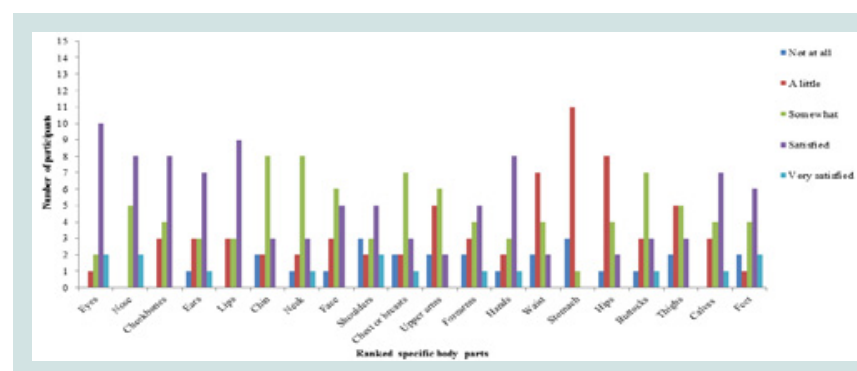

Figure 6: Most and least attractive anterior and posterior rankings from participants before dancing in the bariatric weighted suit. 


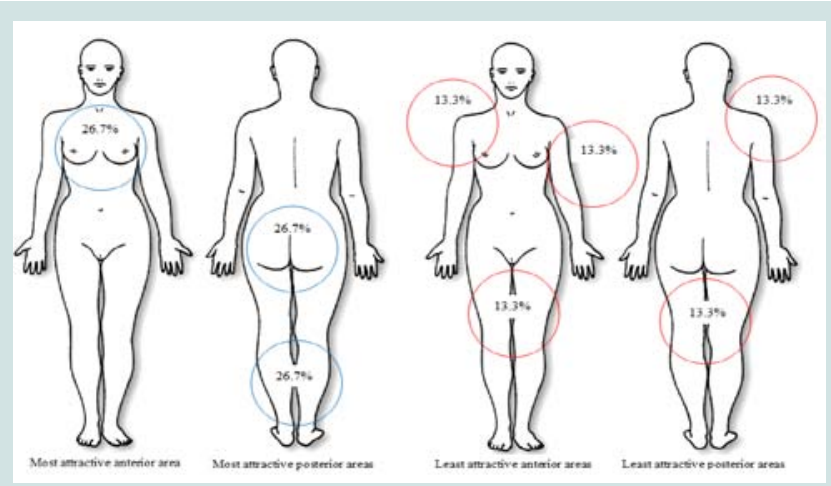

Figure 7: Participants rating on each body part after dancing in the bariatric weighted.

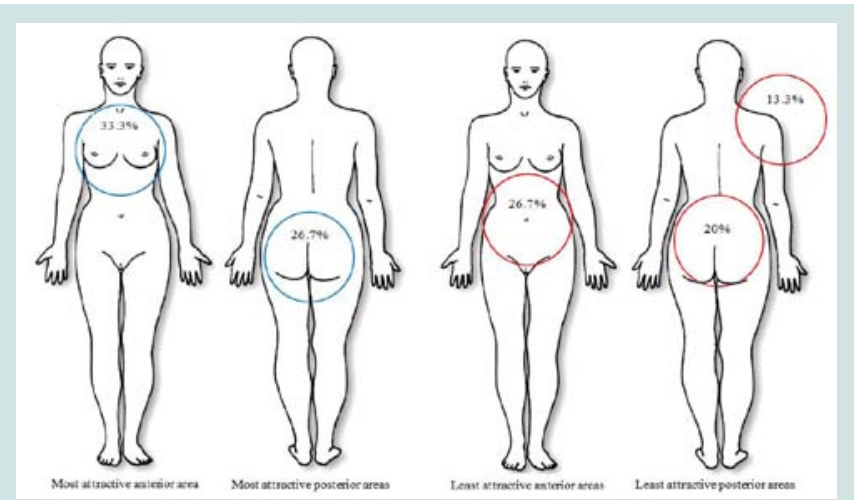

Figure 8: Most and least attractive anterior and posterior rankings from participants after dancing in the bariatric weighted suit.

in the bariatric weighted suit. Results from Figure 8 show that the shoulders were selected as the least attractive body party $(13.33 \%)$. These results suggest that because the females dancers wore the weighted torso as part of the bariatric weighted suit, this drew attention that particular body part.

After dancing in the bariatric weighted suit the number of the participants who wanted to change their stomachs decreased by from $66.7 \%$ to $40 \%$ thus demonstrate that the $26.7 \%$ of the females improved their perception on their stomachs.

\section{Themes from open question on feelings after performance}

The final question was an open question which allowed themes to emerge. Results found participants felt more positive about their body image and more satisfied with their body appearance. This is because the majority stated that they either felt lighter or thinner after dancing in the bariatric weighted suit. Comments made by participants such as: "it made me feel better about my body" (participant 5) and "in comparison to the things that I thought hindered me, aren't actually real problems and I have a better physique than I thought" (participant 10). These results indicate that the bariatric weighted suit provided the participants an experience of what it would be like to be obese and made them question how they now perceive their body after, in comparison. In contrast a small margin of the participants did not feel that differently about their body but it helped them understand that their weight is not a massive issue. However two participants claimed that: "this experience has motivated me to lose some weight" (participant 4) and some participants stated that they were "shocked with the size and weight of the suit" (participant 12) and made them realise that they do not want to become obese.

\section{Conclusion}

University female dancer's perceptions were challenged by wearing a bariatric weighted suit and questioned on their body image. Research aims were addressed and the study revealed that $46.7 \%$ of the participants felt pressure from the media to have a particular body image. Images (see Figure 3) that were rated the most attractive by the participants were similar physiques to professional dancers. It was apparent that certain common areas of the body were being emphasised as negative on the participants' body, such as the stomach and buttock areas. However research suggests that females often overestimated their body image [38]. Results demonstrated that the bariatric weighted suit altered the females' dancers' perception of their own body image, whether it was on a specific body part or a general feeling. For instance, before dancing in the bariatric weighted suit none of the dancers were "satisfied" with their body appearance. Only $33.3 \%$ of them were "somewhat" happy with their body image. When questioned what the participants wanted to change about their body before dancing in the bariatric weighted suit $73.3 \%$ selected their stomach area. After dancing in the bariatric weighted suit the number of participants who wanted to change their stomachs decreased by $26.7 \%$, indicating that the dancers were more content and confident with their body image because it made them recognize and appreciate their body. In conclusion a significant amount of the participants increased in confidence and felt more comfortable with their own body after wearing the bariatric weighted suit. Therefore the bariatric weighted suit has been an integral component within this study because it has challenged the University of Gloucestershire female dance students' perceptions on their body image. Furthermore it provided them with an opportunity to experience what it is like to be obese and appreciate that their body was not as bad as they first perceived.

Within this study, two main limitations were found. Firstly there was a low sample and by having a larger number of participants would have provided more data in which to present more dependable results. Secondly, there was very limited scope in terms of previous research in this area to make compare and contrast arguments, however, on the flip side, as the use of the bariatric weighted suit is at an innovative stage this could provide more opportunities for future research. Recommendations would allow researchers to learn more about the bariatric weighted suit could be used to show younger females who are at a risk of becoming obese and what could happen to their movement and appearance if they fail to act. Another research area would be to recruit non dancers or males to compare and analyse the results from this study, and see if the bariatric weighted suit would challenge their perceptions in the same way.

\section{References}

1. Carlson M, Kiemele R (2016) In the looking glass: an examination of body image and identity development through research and poetry. The Vermont Connection 37: 26-37.

2. Peterson A (2007) The body in question: a socio-cultural approach. New 
Citation: Mills C, Dee S. Challenging Perceptions on Body Image Using a Bariatric Weighted Suit with Female University Dancers. J Obes Bariatrics. 2016;3(1): 6.

ISSN: $2377-9284$

York, USA.

3. Grogan S (2008) Body image: understanding body dissatisfaction in men, women and children. $2^{\text {nd }}$ Editon, New York, USA.

4. Thompson JK, Gardner R (2002) Measuring perceptual body image in adolescents and adults. In: Cash TF, Pruzinsky T (Eds), Body images: a handbook of theory, research and clinical practice. New York, USA, pp. 135141.

5. Tiggemann M (2015) Considerations of positive body image across various social identities and special populations. Body Image 14: 168-176.

6. Blood SK (2005) Body work: the social construction of women's body image J Int Womens Stud 8: 314-315.

7. Rumsey N, Harcourt D (2005) The psychology of appearance. Maidenhead: Open University Press.

8. Grossbard JR, Lee CM, Neighbors C, Larimer ME (2009) Body image concerns and contingent self-esteem in male and female college students. Sex Roles 60: 198-207.

9. Nerini A (2015) Media influence and body dissatisfaction in preadolescent ballet dancers and non-physically active girls. Psychol Sport Exerc 20: 76-83.

10. Bruns GL, Carter MM (2015) Ethnic differences in the effects of media on body image: the effects of priming with ethnically different or similar models. Eat Behav 17: 33-36.

11. Dakanalis A, Carrà G, Calogero R, Fida R, Cleric M, et al. (2015) The developmental effects of medial-ideal internalization and self objectification processes on adolescents' negative body-feelings, dietary restraint, and binge eating. Eur Child Adolesc Psychiatry 24: 997-1010.

12. Andsager JL (2014) Research directions in social media and body image. Sex Roles 71: 407-413.

13. Maltby J, Giles DC, Barber L, McCutcheon LE (2005) Intense-personal celebrity worship and body image: evidence of a link among female adolescents. Br J Health Psychol 10(Pt 1): 17-32.

14. Markula P (1995) Firm but shapely, fit but sexy, strong but thin: the postmodern aerobicizing female bodies. Sociol Sport J 12: 424-453.

15. Heiland TL, Murray DS, Edley PP (2008) Body image of dancers in Los Angeles: the cult of slenderness and media influence among dance students. Res Dance Educ 9: 257-275.

16. Pollatou E, Bakali N, Theodorakis Y, Goudas M (2010) Body image in female professional and amateur dancers. Res Dance Educ 11: 131-137.

17. Candidi M, Aglioti SM (2015) Visual and sensorimotor contributions to the esthetic appraisal of body form, motion, and emotion. Eur Psychol 20: 16-26.

18. Radell SA, Adame DD, Cole SP, Blumenkehl NJ (2011) The impact of mirrors on body image and performance in high and low performing female ballet students. J Dance Med Sci 15: 108-115.

19. Berardi G (2015) Dancing through it: my journey in the ballet/through the eyes of a dancer. J Dance Med Sci 19: 130-131.

20. Penney J (2012) "We Don't Wear Tight Clothes": Gay Panic and Queer Style in Contemporary Hip Hop. Pop Music Soc 35: 321-332.

21. Jackson LA (2004) Physical attractiveness: a sociocultural perspective. In Cash TF, Pruzinsky T (Eds), Body image: a handbook of theory, research and clinical practice. New York, USA, pp. 13-21.

22. Oliver W (2008) Body image in the dance class. J Phys Educ Recreat Dance 79: 18-41.

23. Cohen MJ, Datto GA (2015) Ethical considerations in adolescent bariatric surgery: a case presentation. Clin Pract Pediatr Psychol 3: 365-369.

24. Spectrum Healthcare (2016) Bariatric training suit: Training aid simulates the mass of the bariatric individuals. UK

25. Mills C (2015) What it is like to be obese? A practical example. Obes Res Open J 2: 8-9.

26. Nursing Standard (2013) Bariatric suit used to improve care. Acad J 27: 6-6.

27. Benmor Medical (2016) Bari-Suit: Award winning bariatric training suit improves bariatric care.

28. Ryder JW, Buxton RE, Goetchius E, Scott-Pandorf M, Hackney KJ, et al. (2013) Influence of muscle strength to weight ratio on functional task performance. Eur J Appl Physiol 113: 911-921.

29. Raines MT (1999) Weighted exercise and therapeutic suit. US5937441 A.

30. Rantalainen T, Ruotsalainen I, Virmavirta M (2012) Effect of weighted vest suit worn during daily activities on running speed, jumping power, and agility in young men. J Strength Cond Res 26: 3030-3035.

31. BTS (2016) Bariatric training suit.

32. Franzoi SL, Shields SA (1984) The body-esteem scale: multidimensiona structure and sex differences in a college population. J Pers Assess 48: 173 178.

33. Prieler M, Choi J (2014) Broadening the scope of social media effect research on body image concerns. Sex Roles 71: 378-388.

34. Haas JG (2010) Dance anatomy: your illustrated guide to improving flexibility, muscular strength, and tone. Human Kinetics, Champaign, IL, USA.

35. Robbeson JG, Kruger HS, Wright HH (2015) Disordered eating behavior, body image, and energy status of female student dancers. Int J Sport Nutr Exerc Metab 25: 344-352

36. Selzer RA (2013) Weight matters: african sorority women speak up about body image. Res J Assoc Fratern/Sorority Advisors 8: 16-34.

37. Chacon-Araya Y, Moncada-Jimenez J (2015) An exploration to preferred and non-preferred body parts in university students. J Phys Educ Sport 15.

38. Sarwer DB, Thompson JK (2004) Obesity and body image disturbance. In Wadden TA, Stunkard AJ (Eds), Handbook of obesity treatment. New York, USA, pp. 447- 464 